\title{
INFLUENCE OF BACILLUS PUMILUS ON THE CORROSION OF MILD STEEL IN BIODIESEL
}

\author{
Malarvizhi. $S^{1}$ and Shyamala. $\mathrm{R}^{2}$
}

\begin{abstract}
Biodiesel is considered to be one of the viable forms of renewable energy and plays a significant role in the battle against environmental degradation and global warming. Because of its inherent characteristics, widespread use of biodiesel in the existing infrastructure may cause microbiologically influenced corrosion (MIC). Hence this study aims to investigate the influence of bacteria Bacillus pumilus isolated from the sediments of Jatropha curcas biodiesel on the corrosion of mild steel in biodiesel/petrodiesel blends by mass loss method. Surface morphology was studied using Laser profilometry and SEM.

Keywords: Biodiesel, Microbiologically influenced corrosion, Jatropha curcas, mild steel, Laser profilometry, SEM.
\end{abstract}

\section{I.INTRODUCTION}

Environmental protection, increasing energy demands and energy efficiency are some of the overriding challenges facing worldwide sustainable development. Global warming caused by burning of fossil fuels and deforestation results in the catastrophic failure of ecosystems. Hence the world is focusing on developing alternative energy sources to replace conventional fossil fuels.

A reliable and a continuously renewable resource that can satisfy the needs of society for energy is biomass which can be converted into fuels termed as biofuels. A wide range of feedstock such as energy crops, forest and agricultural residues and algae can be used for the production of biofuels. The two most widely used types of biofuels are ethanol and biodiesel. Being carbon neutral, biodiesel is clean burning, nonpolluting, biodegradable and also an excellent lubricant. It blends easily with petrodiesel in any proportion. With many such advantages biodiesel holds great promise as a sustainable energy source and can be considered an excellent diesel fuel substitute.

Several countries in the world like USA, UK, Germany, Brazil and China have active biodiesel program with legislative support and national policies on biodiesel development. India too has tremendous potential for the biodiesel industry as it has to address the energy challenges [1] facing it.Nonedible plant varieties are the main choice for the production of biodiesel as the use of food crops will reflect indirectly on food security [2]. In India,the availabilities of vast stretches of waste land, tropical climate and manpower provide ideal conditions for growing Jatropha curcas. Jatropha can grow in soils with low fertility and alkalinity. Its oil content is 30-35\% [3] which is higher than that of other oil crops [4]. All these benefits ensure that jatropha is one of the best sources for the production of biodiesel.

Even though biodiesel is valued as one of the promising and sustainable energy sources, its compatibility with different metallic materials is of great concern [5]. When in contact with metals such as brass, copper, tin, mild steel

\footnotetext{
${ }^{1}$ Department of Science and Humanities, Faculty of Engineering, Avinashilingam Institute for Home Science and Higher Education for Women, Coimbatore-641 043

${ }^{2}$ Department of Science and Humanities, Faculty of Engineering, Avinashilingam Institute for Home Science and Higher Education for Women, Coimbatore-641 043
} 
or aluminium which are used for the construction of storage tanks, pipes and pumping equipment, biodiesel and biodiesel blends corrode or form sediments [6].

A type of corrosion that can result in unexpected problems, premature failure and repair is microbiologically influenced corrosion-MIC in which the bacteria and their metabolic products create conditions for corrosion. By virtue of their ready biodegradability, widespread use of biodiesel and its blends with petrodiesel may lead to serious problems of microbial spoilage and corrosion. At present the data available on this topic is scarce and hence knowledge about the nature of microbes that survive in biodiesel and the ingredients that help in their growth will help us control MIC.

This paper aims to study the influence of Bacillus pumilus, bacteria isolated from the sediments of stored Jatropha curcas biodiesel [7] on the corrosion of mild steel in Jatropha curcas biodiesel and its blends with commercial diesel.

\section{MATERIALS AND METHODS}

\section{A. Corrosion rate determination by mass loss method}

Mild steel coupons of size $7.5 \times 1.9 \times 0.3 \mathrm{~cm}$ with holes drilled on the top center of the coupons were used for the corrosion study. Mild steel coupons were polished with 200, 600 and 800 grit emery paper and then degreased using trichloroethylene.

Jatropha curcas biodiesel (JBD) was purchased from a biodiesel exporter in India and commercial diesel (CD) was purchased from a nearby petrol bunk.

The corrosion studies were carried in five fuel mixtures:

- $\mathrm{B} 100-100 \% \mathrm{JBD}$

- $\quad$ B20 $-20 \%$ JBD and $80 \% \mathrm{CD}(\%$ by volume $)$

- $\quad$ B10 $-10 \%$ JBD and $90 \%$ CD (\% by volume)

- $\quad$ B5 - 5\% JBD and 95\% CD (\% by volume)

- $\quad$ D $\quad-100 \%$ commercial diesel

The control system consisted of fuel mixture with $2 \%(\mathrm{v} / \mathrm{v})$ water containing 500ppm chloride to simulate corrosion conditions. The experimental system consisted of fuel mixture with $2 \%(\mathrm{v} / \mathrm{v})$ water containing 500ppm chloride and $0.5 \%(\mathrm{v} / \mathrm{v})$ of bacterial inoculum (a load of $\left.1 \times 10^{6} \mathrm{CFU} / \mathrm{ml}\right)$

The mass loss measurements were carried out using ASTM G1 standard. Previously weighed metal coupons were immersed in the fuel mixtures and agitated using a magnetic stirrer. After $100 \mathrm{~h}$, the coupons were removed and pickled in pickling solutions (ASTM G3), washed with water and dried. Final masses of the coupons in each system were taken and the mean corrosion rates (in triplicates) were calculated and expressed in mils per year (mpy).

\section{B. Surface analysis by Laser Profilometry}

A Zeta-20 True color 3D Optical Profiler was used to map the surface topography and determine the pit distribution and depths for the metal samples immersed in the control and experimental systems of B100.

\section{Surface analysis by Scanning Electron Microscopy (SEM)}

For SEM studies, the surface of the coupons exposed to B100 and CD fuel mixtures for $100 \mathrm{~h}$ were used.The coupons were exposed to $2.5 \%$ gluteraldehyde for $8 \mathrm{~h}$ and subsequently washed with a graded series $(30 \%, 50 \%$, 
$70 \%$ and $100 \%$ ) of ethanol for dehydration. The samples were then coated with gold alloy prior to SEM observations. The entire surface area of the coupon was examined to locate sessile bacteria.

\section{RESULTS AND DISCUSSION}

\section{A. Mass loss measurement}

Table 1. Corrosion rates of mild steel in the control and experimental system

\begin{tabular}{|c|c|c|c|c|c|}
\hline $\begin{array}{c}\text { Average } \\
\text { Corrosion Rate } \\
(\text { mpy) }\end{array}$ & \multicolumn{5}{|c|}{ Medium } \\
\cline { 2 - 6 } & $\mathrm{B} 100$ & $\mathrm{B20}$ & $\mathrm{B} 10$ & $\mathrm{~B} 5$ & CD \\
\hline Control system & $6.09 \pm 0.1824$ & $0.57 \pm 0.0553$ & $0.64 \pm 0.0311$ & $0.72 \pm 0.2039$ & $4.60 \pm 0.3034$ \\
\hline $\begin{array}{c}\text { Experimental } \\
\text { system }\end{array}$ & $2.30 \pm 0.0253$ & $0.45 \pm 0.1178$ & $0.83 \pm 0.0966$ & $0.98 \pm 0.2003$ & $22.21 \pm 1.6977$ \\
\hline
\end{tabular}

The corrosion rates of mild steel in the control and experimental systems are given in Table 1.In the control system the corrosion rate of mild steel is the highest in B100 which is in accordance with the fact that biodiesels are more corrosive than petrodiesel due to the presence of unconverted monoalkyl esters, free fatty acids and water content $[6,8]$.But in the experimental system,mild steel exhibits the highest corrosion rate of $22.21 \mathrm{mpy}$ in CD. In B100, the corrosion rate is only 2.30 mpy.Lee et al. [9] also observed that a carbon steel sample exhibited the highest corrosion rate in ultra-low sulphur diesel (ULSD) and the lowest corrosion rates in biodiesel containing fuels. When the corrosion rates of mild steel in the control system are compared with that of the experimental system, there is a vast difference between corrosion rates of mild steel in the control system and in the presence of Bacillus pumilus for CD.In B100 and B20, there is a decrease in the corrosion rate in the presence of Bacillus pumilus when compared to the control system while it is the reverse in the case of B5 and B10 blends and in CD.It is also observed that in both the control and experimental systems, the corrosion rates of mild steel decrease with increasing concentration of biodiesel in the blends. In a similar study on carbon steel[10] carried out in the absence and presence of Bacillus pumilus, it was observed that the corrosion rates of carbon steel increased with increasing concentration of biodiesel in the blends, which is in contrast to the results obtained in the present study.

\section{B. Surface analysis by laser profilometry}

The surface topography of corroded materials can be studied using laser profilometry without altering the sample surface through physical contact. Surface profiles (3D), pit distributions and roughness parameters of mild steel samples in B100 (control and experimental systems) are described.

The surface profile for mild steel in B100 for the control system is presented in Figure 1, and the pit distribution histogram of the mild steel sample is given in Figure 2.

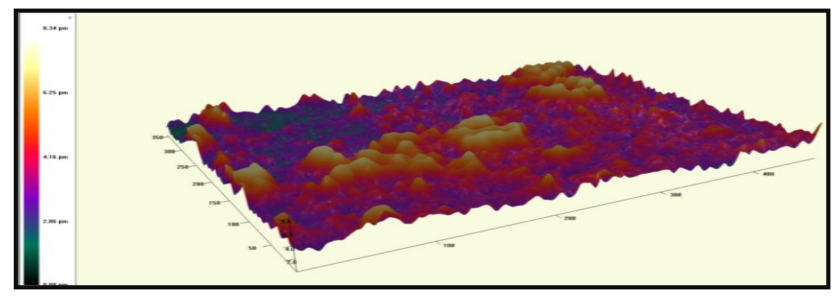

Figure 1.Surface profile (3D image) of mild steel in control system (B100)

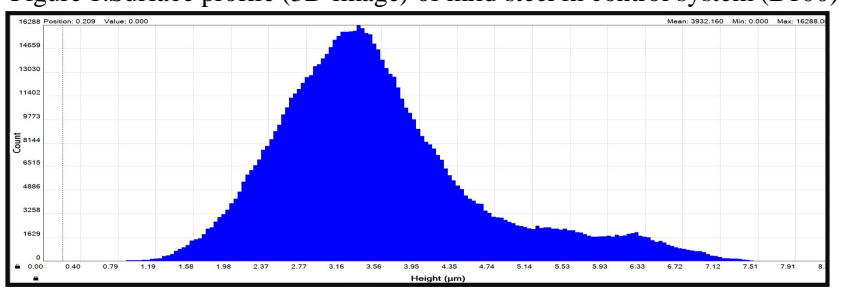


Figure 2.Pit distribution histogram of mild steel in control system (B100)

The surface profile for mild steel in B100 for the experimental system is presented in Figure 3 and the pit distribution histogram of the mild steel sample is given in Figure 4.

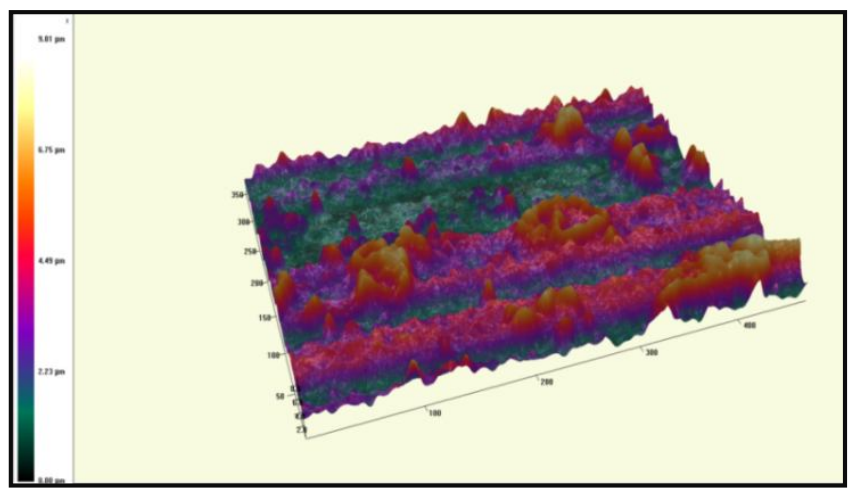

Figure 3.Surface profile (3D image) of mild steel in experimental system (B100)

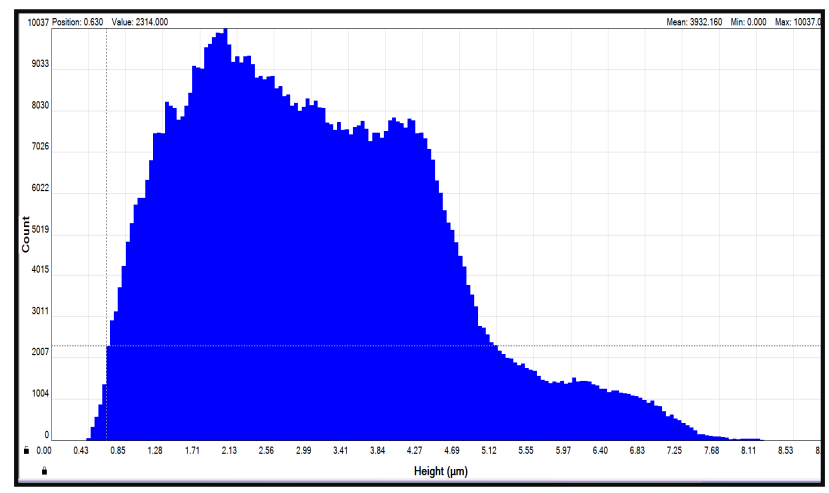

Figure 4.Pit distribution histogram of mild steel in experimental system (B100)

Corrosion is a surface phenomenon and hence surface roughness which is a measure of texture of a surface is significant in corrosion studies. It is quantified by the vertical deviations of a real surface from its ideal form. If these deviations are large, the surface is rough; if they are small the surface is smooth. The roughness indicates how the real object will interact with the environment and hence often predicts corrosion of metal surfaces. The roughness value is either calculated on a profile (line) or on a surface (area). But the profile roughness parameters are more common. Of the many different roughness parameters used, the most common parameters are $R_{a}, R_{q}$ and $\mathrm{R}_{\mathrm{t}}$. These parameters are of statistical nature.

$\mathbf{R}_{\mathbf{a}}$ is the arithmetic average of the roughness profile. $\mathbf{R}_{\mathbf{q}}$ also known as $\mathbf{R}_{\mathrm{rms}}$ is the root mean square average between the height deviations and the mean line taken over the evaluation length. It describes the finish of optical surfaces. $\mathbf{R}_{\mathbf{t}}$ represents the maximum height - the vertical distance between the highest and lowest point. It describes the overall roughness of the surface. 
In the present study, the profilometric mean roughness parameters $R_{a}, R_{q}$ and $R_{t}$ were determined automatically from the surface profile of the metal. Three profilometric scans were taken at different positions on the metal surface, and the mean and the standard deviation were calculated and the results are tabulated below.

Table 2.Roughness parameters for mild steel

\begin{tabular}{|c|c|c|c|c|c|c|}
\hline \multirow{2}{*}{} & \multicolumn{3}{|c|}{ Control } & \multicolumn{3}{c|}{ Experimental } \\
\cline { 2 - 7 } & Ra $(\boldsymbol{\mu m})$ & Rq $(\boldsymbol{\mu m})$ & $\mathbf{R}_{\mathbf{t}}(\boldsymbol{\mu m})$ & Ra $(\boldsymbol{\mu m})$ & Rq $(\boldsymbol{\mu m})$ & $\mathbf{R}_{\mathbf{t}}(\boldsymbol{\mu m})$ \\
\hline I & 0.5197 & 0.6343 & 3.524 & 0.6990 & 0.8491 & 3.661 \\
\hline II & 0.6591 & 0.8246 & 3.987 & 0.4888 & 0.6923 & 4.230 \\
\hline III & 0.7769 & 0.9611 & 4.309 & 0.6859 & 0.8706 & 4.351 \\
\hline Mean & $\mathbf{0 . 6 5 1 9}$ & $\mathbf{0 . 8 0 6 7}$ & $\mathbf{3 . 9 4 0}$ & $\mathbf{0 . 6 2 4 0}$ & $\mathbf{0 . 8 0 4 0}$ & $\mathbf{4 . 0 8 1}$ \\
\hline SD & $\mathbf{0 . 1 0 5 1}$ & $\mathbf{0 . 1 3 4 0}$ & $\mathbf{0 . 3 2 1 9}$ & $\mathbf{0 . 0 9 6 1}$ & $\mathbf{0 . 0 7 9 5}$ & $\mathbf{0 . 3 0 0 9}$ \\
\hline
\end{tabular}

The influence of the bacteria on the surface of mild steel is minimal compared to the control system since the change in the roughness parameters is not much.From the laser profile data no correlation could be established with mass loss results since mass loss describes the general corrosion while laser profile details localized corrosion.

\section{Surface analysis by scanning electron microscopy}

Figure 5 shows the SEM micrographs of mild steel in B100 and CD after exposure to the bacterial system, without removal of corrosion products on the metal surface. It is very clear that the coupons are covered with corrosion products and the products formed are dense and lumpy in B100 as well as in CD.

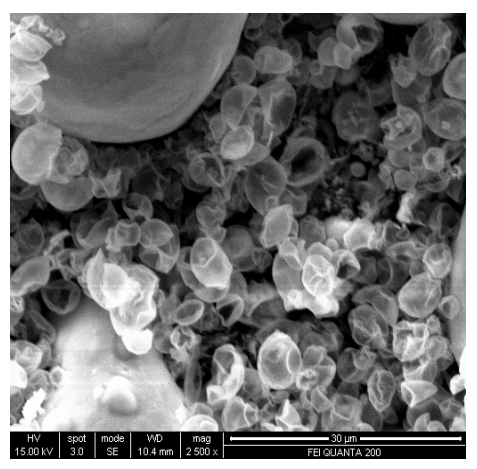

(a)

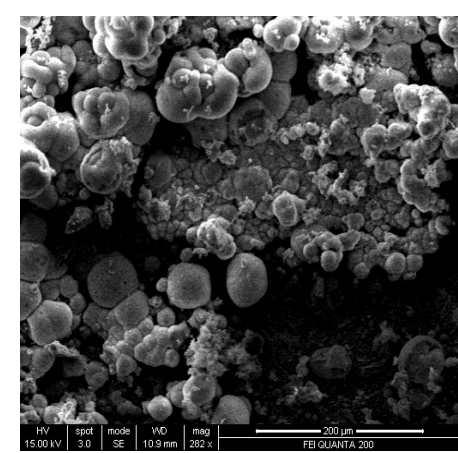

(b)

Figure 5.SEM images of mild steel (a) B100 and (b) CD in the experimental system

\section{IV.CONCLUSION}

- Mild steel suffers the highest corrosion rate in CD in the presence of Bacillus pumilus.

- In the control system mild steel shows the highest corrosion rate in B100.

- It is observed that in the presence of Bacillus pumilus, the corrosion rates of mild steel in B100 and B20 blends have decreased when compared to the control. 
- In the blends the corrosion rates of mild steel decrease with increasing concentration of biodiesel.

\section{ACKNOWLEDGEMENT}

The authors would like to thank the authorities of Avinashilingam Institute for Home Science and Higher Education for Women, Coimbatore-641043, Tamilnadu, India for providing the necessary facilities for carrying out this work.

\section{REFERENCES}

[1]. C.Pathak, H.C.Mandalia, Y.M.Rupala, "Biofuels: Indian energy Scenario”, Research journal of Recent Sciences, vol.1, pp. 88-90, 2012.

[2].R. T. Gahukar, "Food security: The challenges of climate change and bioenergy", Current Science, vol.96, pp.26-28, 2009.

[3].W.M.J. Achten, L.Verchot, Y.J.Franken, E .Mathijs, V.P. Singh, R .Aerts, B. Muys, "Jatropha bio-diesel production and use", Biomass Bioenergy, vol.32, pp.1063-1084, 2008.

[4].N. Foidl, G. Foidl, M .Sanchez, M. Mittelbach, S .Hackel, "Jatropha curcas L. as a source for the production of biofuel in Nicaragua", Bioresource Technology, vol.58, pp. 77-82. 1996.

[5]. A.S.M.A .Haseeb, M.A. Fazal, M.I.Jahirul, H.H .Masjuki, "Compatibility of automotive materials in biodiesel: A review", Fuel, vol.90, pp.922-931, 2011.

[6]. R.D.Kane and S.Papavinasam, "Corrosion and SCC issues in fuel ethanol and biofuels", NACE Corrosion Conference (CORROSION 2009), Paper No.09528, 2009.

[7]. S.Malarvizhi, R.Shyamala, S.Papavinasam, “Assessment of Microbiologically Influenced Corrosion of Metals in Biodiesel from Jatropha curcas", NACE Corrosion Conference (CORROSION'15), paper No.5772, 2015.

[8]. M.A. Fazal, A.S.M.A .Haseeb, H.H .Masjuki, "Biodiesel feasibility study: An evaluation of material compatibility, performance, emission and engine durability", Renewable and Sustainable Energy Reviews, vol.15, pp.1314-1324, 2011.

[9]. J.S.Lee, R.I.Ray, B.J.Little, "Microbiological and corrosivity characterizations of biodiesels and advanced diesel fuels", NACE CORROSION 2009, Paper No.09529.

[10].S.Malarvizhi and R.Shyamala, "Microbiologically Influenced Corrosion of Carbon Steel Exposed to Biodiesel”, International Journal of Corrosion, vol.2016, 2016. 